\title{
COP20's ethical fallout: The perils of principles without dialogue ${ }^{1}$
}

\section{Hugh Breakey}

\section{Abstract}

The Lima COP20 Outcome Document employs ethical language when it envisages that Parties consider how their carbon mitigation contributions are "fair and ambitious". However, this article stresses the serious omission of any 'ex-ante consideration' or 'strategic review' mechanisms requiring official review of such justifications. Such mechanisms (currently lying dormant in the Elements Text for the Paris negotiations) offer the promise of genuine moral dialogue, capable of pressuring states to shoulder greater burdens, and of forcing them to revise or mitigate self-interested or parochial rationalizations. I show how key climate principles derive from prior arguments, reasons and ethical judgments - meaning that a process of moral dialogue can constructively engage with these prior commitments. To illustrate the possibilities, I draw parallels to the drafting process of the Universal Declaration of Human Rights, where moral dialogue shifted states from simplistic, self-serving parochial assertions to productive consensus.

\section{Introduction}

The Outcome Document resulting from the COP20 in Lima 2014 employs just a tincture of ethical language. The Document envisages Parties may communicate how their intended nationally determined contributions (INDCs) to global carbon mitigation are 'fair and ambitious' (COP20, 2014b, para. 14). In all likelihood, this language, and the communications it recommends, will do little to improve the effectiveness or legitimacy of climate negotiations and action. However,

\footnotetext{
${ }^{1}$ This is the postprint version of Hugh Breakey, @COP20's Ethical Fallout: The Perils of Principles Without Dialogue" (2015) 18(2) Ethics, Policy \& Environment 156-169, available at: http://www.tandfonline.com/doi/abs/10.1080/21550085.2015.1070520?journalCode=cepe21
} 
embedded within the current Elements Text for the Paris negotiations (COP20, 2014a, paras. 76, 8087) are two mechanisms for subsequently engaging in a public dialogic process with Parties' claims regarding their INDC's fairness. I argue that these mechanisms, if adopted as part of the post-Paris regime, could well propel an international moral dialogue about the principles of climate justice. What the global climate regime requires, and what such a review process could capture, is movement beyond the strategic selection of broad climate justice principles, towards a rational discussion about what specific principles, in combination with what other principles, in what interpretations, are morally legitimate.

I begin the argument in Section I by outlining several existing features of moral argument and language in contemporary climate discourse. In particular, I suggest that the nature of climate principles (as 'practical norms') offers a space for increased understanding and consensus through moral dialogue. I then describe what I mean by 'moral dialogue' in this context. In Section II, I provide an illustrative account of a successful example of the process I have in mind - the drafting of the Universal Declaration of Human Rights from 1946-1948. In this process, states were forced to move beyond mere assertion of (their conflicting) principles. State delegations were confronted with sustained enquiry, rational deliberation, suggested modifications, and external judgment upon their stated reasons for those principles - ultimately leading to a surprising and productive level of sophistication, specificity, compromise and consensus. In Section III, we return to the pressing concern with climate change. I survey the moral language and processes envisaged in the Lima Outcome Document, and the existing Elements Text for Paris. In Section IV, I explain how the review process could drive a moral dialogue similar to that achieved by the Universal Declaration process, with similar potential for improving understanding and consensus. 


\section{Ethical discourse and climate change}

\section{Ethical language and argument in contemporary climate discourse.}

I begin this section by sketching four broad-brush features of the existing nature of moral language, reasoning, theorizing and dialogue in climate discourse. (Section III will detail recent developments specific to COP20 and the current draft text for Paris negotiations.)

Feature One: Climate discourse employs moral language, but not moral dialogue

Like most policy discourse, ethical ideas and values permeate discussions of climate. In particular, the United Nations Framework Convention on Climate Change ((IPCC), 1992) itself, and the Rio and Kyoto agreements, invoke an array of what we can term 'climate principles', including equity, sustainable development, polluter-pays, historic responsibility and 'common but differentiated responsibilities' ((ILA), 2014; Maguire, 2012).

However, even when such climate principles are invoked, there is usually little reflection on their substance or their relation to other ethical concerns (COMEST, 2010, pp. 5, 38). Speakers perennially fail to articulate exactly what the principle requires, why this interpretation and application of this particular principle is an appropriate one, and how the principle relates to alternative (perhaps countervailing) principles. In short, the political and public discourse does not display moral argument or reasoning - just the assertion of claims of fairness or the invocation of selected principles.

And that is the good news. All-too-often, such moral language is eschewed entirely, and climate issues are seen through other lens, such as scientific and economic discourses (Brown, 2013; Christoff, 2013). Recent work by Donald Brown and Prue Taylor (2014) shows that nations employ little explicit ethical reasoning and argument in determining and defending their emissions pledges a situation climate scholars have long observed (Okereke, 2010, pp. 466-467). 
In short, often climate discourse completely avoids employing moral language. Even when moral language is used, genuine moral dialogue and discussion rarely occurs (in the next section I explain more fully what I mean by 'moral dialogue' in this context).

\section{Feature Two: The level of moral disagreement}

The presence of the above-noted climate principles in the major documents and agreements suggest that the international community recognizes the major moral issues implicated by climate change. The fact that significant substance can be imputed to several of the agreed climate principles ((ILA), 2014; Maguire, 2012) implies there is a level of widespread agreement on at least some of the key moral issues.

But this level of agreement must not be over-stated. For one thing, the inability to secure effective agreements for practical collective action on climate mitigation in the decades since 1992 implies that deep divisions remain. Moreover, these divisions are explicitly evidenced in ongoing disagreements on the nature and significance of some of the climate principles. A case in point is the principle of 'common but differentiated responsibilities'. While the Kyoto Protocol initially made a clear distinction between the nature of the obligations (whether they were legally binding or not) on the basis of Annex I (developed country) Parties versus non-Annex I (developing country) Parties, there is at present substantial ambiguity bedeviling the basis on which differentiation should occur in the post-Paris regime, and what that differentiation should mean in practice (Maguire, 2013, pp. 3-7). As such, two Parties might both invoke the principle of 'common but differentiated responsibilities', but understand that principle in diametrically opposing ways (Okereke, 2010, p. 469). 'Historic responsibility' for past emissions is another area where deep divisions arise (Okereke, 2010, p. 465).

Feature Three: Almost no nation lives up to minimum requirements of any reasonable moral position A further feature of climate ethics is that it is hard to find almost any state Party - and certainly any developed country - that lives up to what we might term the 'minimum requirements' of justice or 
morality. By this invocation of 'minimum requirements', I acknowledge that there are an array of legitimate, consistent moral positions one can hold with respect to the demands of climate justice. Some of these alternatives might be more justifiable than others, but they each stand up to what Brown calls 'minimum ethical scrutiny' $(2013$, p. 171). I will call these legitimate, consistent alternatives that can stand up to basic scrutiny, 'reasonable moral positions'. Yet, the existence of this array of reasonable moral positions does not mean that anything goes. Every reasonable moral position demands more aggressive action, especially on the part of developed countries, than they are currently performing, and appear willing to perform (Ott, 2011). This is so even for the most generous positions that a developed country might select, such as the limited grandfathering options that allow states to emit more carbon on the basis of their current reliance on carbon arising from their historical emissions (Knight, 2012).

To be clear, many theorists would debate whether grandfathering even should be recognized as a reasonable moral position at all. (It is counter-intuitive to think that a nation that is more responsible for a problem should enjoy more entitlements because of that prior responsibility.) But even if we allow that limited grandfathering counts as a reasonable moral position, it remains the case that developed countries are not doing enough.

\section{Feature Four: Climate principles as practical norms}

The final feature concerns the nature of the aforementioned 'climate principles'. I want to spend a little time on this feature because it holds direct consequences for the possibility of moral dialogue.

The word 'principles' is ambiguous. 'Principles' can refer to fundaments - irremovable base level commitments that serve as the ultimate premises of our ethical arguments and chains of reasoning. But 'principles' can also refer to applied, practical norms that result from ethical argument. In other words, and as Aristotle $(2002,1095 a 30)$ observed long ago, one can argue from principles (as fundaments), or towards them (as practical norms). 
When it comes to arguing over fundaments, discussion may not be much help in resolving disputes. The millennia-old disputes of Western philosophy illustrate the difficulties with achieving resolution here (Maclntyre, 1981), and discussion over fundaments often can do little more than pointlessly echo the dull thud of conflicting base-level intuitions.

But debates over practical norms present a different species entirely. Because practical norms are conclusions of arguments, dialogue can engage with the process of reasoning that led to them. Perhaps, on reflection, it can be shown that those lines of reasoning should include extra considerations, or perhaps they contain faulty empirical claims, or subtle errors in logic. Perhaps they can be shown to lead to surprising and unwanted consequences, driving their erstwhile holder to reflect and revise them.

The climate principles I have been discussing are such practical norms. They rest upon prior chains of argument, and are defined by these. For example, the meaning and substance of 'polluter pays' rests upon an array of factors regarding the significance and substance of harm, the meaning of 'pollution' (especially in a case where high-levels of an otherwise innocuous molecule like carbon dioxide create grave problems), whether 'payment' involves trading for emission entitlements or being fined for wrongful emissions, and so on. The principle might be defended on the basis of the (utilitarian) public interest and greater good, or grounded in (deontological) human rights.

As a result, asserting a commitment to 'polluter pays' does not end common-sense moral enquiry into how that principle should be understood, and what it means practically in the context of climate mitigation efforts.

Equally, one can interrogate 'historical responsibility', asking whether the notion of 'responsibility for harm' being invoked gels with commonsense or existing legal notions of harm, and whether this notion of harm is applied consistently across other (e.g. non-climate) contexts. And similarly for the other climate principles - assertion of these principles need not end rational debate about fairness and ambition, but rather help us begin that debate. 


\section{What do I mean by moral dialogue?}

This point about climate principles as practical norms helps explain what I mean by moral dialogue. By moral dialogue I refer to processes of collective reasoning and common-sense deliberation about practical norms and their application.

Moral dialogue is thus not about simply selecting and asserting a given norm, but involves reflecting on that norm, considering exactly what it requires, and what might be said in support of it and in critique of it. This process might well impel revision or specification of the norm - or even rejection of it.

Conceived in this way, moral dialogue needs to be distinguished from two other processes with which it might be confused.

The first process is good-faith negotiation on solutions to collective problems. A purely selfinterested agent, faced with a collective-action problem, will have reason to strategically engage with other agents in order to come to a collective solution. In so doing, the agent will doubtless have to compromise in various ways in order to secure the necessary compromises from others, and so to solve the collective problem. She may well engage in negotiations in 'good faith' - meaning that she genuinely wants to achieve a collective solution, and fully intends to live up to her agreed commitments in order to secure that objective. But the process she enters into does not constitute moral dialogue as I am using that phrase. The self-interested agent is not interesting in securing a just outcome to the problem - she is interested only in shouldering the minimum burdens necessary to ensure the agreement and compliance of other agents in the group (and only in solving the problem to the extent that doing so furthers her narrow self-interest). The solution she successfully negotiates may have little to do with what objective norms of justice would require. In fact, bargaining solutions can work directly again moral outcomes. For instance, the Nash bargaining solution, widely influential in economics, sees those with the least to lose from failed negotiations effectively holding out for their most desired outcomes (Muldoon et al., 2014, pp. 385-387). The 
solution favors existing power relations, which can diametrically oppose common-sense and theoretically-grounded moral considerations (Muldoon et al., 2014, p. 386).

So too, self-interested negotiation can, at best, result in compromise, but not in synthesis. As Martin Benjamin (1990, pp. 5-7) explains this important distinction, compromise does not involve a change in one's view on the best way forward, but instead requires acquiescing to a practical concession between what one wants and what others demand. Despite holding firm to one's view, for example, one might compromise to achieve a workable agreement. Synthesis, on the other hand, involves actually changing one's own standpoint. This might occur in moral dialogue, for example, when one has been persuaded of the attractions of another's position. Good faith negotiation will usually require compromise, but not the genuine revisiting of one's larger objectives and moral principles that facilitate synthesis.

The second process I wish to distinguish from moral reasoning is that which occurs within what John Rawls called 'comprehensive doctrines', where very specific and substantive (often metaphysical or religious) beliefs are used to determine fundamental principles or applied prescriptions for action. Moral dialogue, ${ }^{2}$ similar to Rawls' 'public reason' (Dreben, 2003; Rawls, 2005, pp. 440-490), resists descending into such difficult terrain. It allows common-sense modes of moral and rational deliberation to occur without resort to controversial fundaments. By avoiding such fundaments, moral dialogue can proceed beyond parties simply asserting their immovable principles on the basis of their deeply held comprehensive doctrines. Instead, moral dialogue involves a rational discussion about what principles, in combination with what other principles, in what interpretations, are justified.

\footnotetext{
${ }^{2}$ Rawls would perhaps prefer the term 'political' rather than moral. However, in this context employing 'political' would distract from the focus on developing and debating a specifically ethical (though not comprehensive) position.
} 
Thus, moral reasoning is in some sense quite 'minimal'; it does not require full-throttle metaphysical defense of ethical fundaments, nor appeal to particular religious or ethical traditions. Conversely though, moral reasoning is still ethical in nature - it requires more than the strategic compromise of a good-faith but self-interested negotiator.

\section{Can moral dialogue, so understood, aid climate mitigation efforts?}

So far I have provided an account of moral dialogue, and claimed that such dialogue is more or less absent from existing climate discourse. But is this absence important? After all, often justifiable results can be negotiated without moral dialogue. The balance of power, the structure of the negotiations, or the parties' intuitive decency, might lead to fair outcomes. Indeed, sometimes the invocation of moral principles can be, itself, problematic, stymieing possibilities for reasonable compromise by encouraging unyielding stances (Benjamin, 1990).

What, then, might we hope an injection of moral dialogue could achieve? Recall two features of the current climate discourse already discussed. First, there is substantial disagreement on key climate principles (such as 'common but differentiated responsibilities). Second, very few countries comply with the minimum requirements that would be demanded by any reasonable moral position.

Consider also that negotiations so far have failed to achieve a just or effective agreement capable of achieving the ultimate objective of the Framework Convention (namely, to stabilize greenhouse gas concentrations at a level that prevents 'dangerous anthropogenic interference with the climate system' (Art. 2).)

With these existing features in mind, moral dialogue could hope to achieve two specific objectives.

First, by getting all nations to explicitly advance and defend a reasonable moral position (recall this is a consistent, plausible ethical standpoint that passes Brown's 'minimal ethical scrutiny'), we encourage the possibility that each state Party will shift their actual negotiating position towards one according with reasonable moral demands. In other words, one of the problems we face is not merely that nations disagree on what is morally required, but that because nations do not speak in 
clear moral terms, most of them get away with doing far less than any reasonable moral position would require (Brown, 2013; Ott, 2011). Forcing Parties to announce and defend a reasonable moral position, and to show how their INDCs accord with its demands, would pressure each nation into living up to those demands. This would improve the ambition of each Parties' INDCS even if those Parties deliberately selected a reasonable moral position that was as favorable as possible to their own self-interest. As I argued earlier, even the most generous reasonable moral positions require more action that is currently being done. Most of the actual negotiations, and the processes by which states come to their domestic positions, resemble more the strategic compromises of our selfinterested negotiator flagged in the previous subsection. Moving from strategic negotiation to moral dialogue might therefore elicit a substantial increase in the ambition of Parties' INDCs.

Second, moral dialogue can elicit genuine changes in the moral position one has staked out. As explained above, moral dialogue is about more than selecting and cleaving to a particular position, but engaging in collective reflection on that position. For this reason, consensus - or at least an increased accord across alternative positions - is possible.

It seems plausible to think that if states begin to narrow the extent of their disagreements on the moral substance of climate justice, and of the climate principles in particular, that a genuine and effective way forward will be easier to achieve. In fact, in the context of climate mitigation efforts, we have a special reason to require an agreement that each nation can see as adequately legitimate. Without such perceived legitimacy, aggrieved nations will have no reason to honor the agreement except through fear of exposure and punishment. But climate mitigation efforts resemble large-scale prisoner's dilemmas like common property arrangements, rife with opportunities for free-riding and hidden defections. As Ostrom and Hess (2007, p. 29) describe in that context: 'When participants do not look upon such rules as legitimate, effective, and fair, the capacity to invent evasive strategies is substantial.' As such, if all parties cannot morally endorse the agreement itself, they will all too easily find ways to avoid implementing its demands. If that is right, then we require the genuine synthesis 
made possible by moral dialogue, and not the strategic compromise driven by self-interested negotiation.

Summing up, if Parties did engage in a genuine, sustained process of moral reasoning, we could expect changes in two directions. First, the positions they put forward (in the shape of their INDCs) might move increasingly towards policies defensible from at least one reasonable moral position. In every case, this would result in an increase in the ambition of the INDCs. Second, the Parties might modify and revise their moral positions in various ways as they engage in moral dialogue, bringing their various stances closer together.

Some might object that this all sounds quite naïve, given the harsh realities of international realpolitik. How do we know that moral dialogue can help compliance and achieve increased accord? Because it has happened before. To provide a clearer understanding of what moral dialogue looks like, and what it can achieve, we turn now to reflect upon the drafting process of the Universal Declaration of Human Rights.

\section{A case-study: The Universal Declaration of Human Rights.}

The drafting process of the Universal Declaration of Human Rights (General-Assembly, 1948) provides a key example of a case where initial, specious assertions of a practice or policy's justifiability caved in to scrutiny, debate and peer judgment. Such changes occurred in cases where states were engaging in bad faith attempts to put a moral gloss on patently immoral actions, but also in cases where states began with parochial or ideological standpoints that they later came to mitigate or revise.

As with climate change, states had powerful reasons to come together and craft a substantive agreement (Glendon, 2001; Morsink, 1999). The Second World War had showcased the horrors oppressive states can inflict on human dignity, especially when fuelled by fascist and racist ideologies. The UN Member States shared the conviction that these ideologies had fomented not only domestic atrocities, but ignited international aggression. So too, the Allied Powers had rallied 
under Roosevelt's declaration of the 'Four Freedoms', and many nations felt that the hard-fought peace must reflect those noble values. The presence of human rights in the UN Charter of 1945 exemplified this expectation, and created a positive, quasi-legal pressure for delineating those rights.

Equally though - and again as with climate change - each individual state possessed potent reasons to resist clear, strong human rights. Human rights fundamentally constrain the power of governments to pursue their agendas - including their ideological commitments, and their naked will to hold on to power. Furthermore, even as they impose constraints, human rights hold up a positive standard of achievement by which states can be judged, and international pressure applied to them if they are found wanting (Beitz, 2009). In the mid-late 1940s, many states had reasons to be wary of human rights: the US was struggling with racial discrimination; much of Western Europe reigned over brutal colonial empires; and the Soviet bloc was tightening its hold on power through mass repression of its citizens.

As a result, states were under positive collective pressure to engage in moral reasoning and argument to achieve a productive consensus - even as they were each individually motivated to weaken and efface any measures that might highlight their own faults or expose them to demanding new duties. Given these countervailing pressures, we might expect states to attempt to use various types of moral rhetoric to cover their own inadequacies. Even as we find exactly this, the historical record shows that constructive dialogue ultimately exposed bad faith interventions and persuaded states with parochial and self-interested positions to mitigate, shelve and (sometimes even) actually change those views.

To show this, I cite some illustrative ways this process occurred, including: exposures of bad faith argument; genuine change on the basis of moral argument; and revisions of asserted positions due to peer judgments and the wish not to (be seen to) block the necessary consensus.

By 'bad faith' arguments I refer to cases where Member States held clearly vested interests on which basis they attempted to influence the text in order to limit the obvious clashes between the 
Declaration and their current actions - but without mounting an explicit and up-front defense of those actions. In these cases, the states seemed well aware that their actions were publically indefensible, but sought to alter their potential exposure to the demands of the Declaration through appeal to various other moral reasons and principles. Bad faith arguments of this sort littered the process, from Western colonial empires limiting reference to the human rights of colonized peoples, to Soviet discrimination against political dissidents, to some religious states trying to weaken women's equality in marriage (Morsink, 1999).

But the most obvious example of bad faith engagement was the rhetoric of South Africa, whose reigning system of apartheid breached the anti-discrimination requirements and universal application implicit (and often explicit) in every one of the Declaration's articles. A prime example occurred when the South African delegate moved to purge references to human dignity on the basis that there was no 'universal standard of dignity'. One of drafters recounts how this motion 'so electrified the meeting' that the entire membership - East and West alike - united in protest (Glendon, 2001, p. 144). Rapidly shifting gear, the following day the South African delegate tried another tack, 'clarifying' that the problem was that the Declaration should be a statement of rights, and that dignity should be excluded as it was not a right (Glendon, 2001, p. 145). This proposal fared little better. Indeed, it is difficult to find any bad faith arguments that managed to seriously impact upon the substance and reach of the final document. Ultimately, despite the worst intentions of various states, human rights could not be blocked in their application to women, colonized peoples and state dissidents (Risse \& Sikkink, 1999; Thomas, 2001).

Moving from the deliberate obfuscation in bad faith arguments to the more general problem of parochial, self-interested or ideological values, the record shows that common-sense moral argument did manage to persuade state delegations to shift or alter their views, or to at least persuade voting allies of those states to side against it on the issue in question. Typical arguments and queries included: whether the state would accept a similar entitlement in a different but 
relevantly analogous application; whether the proposed principle could or had been used as rhetorical cover by an evil (i.e. Nazi) regime; whether the proposed ground for the rights could be endorsed by all people; whether the principle would allow the Declaration to fulfil the public's expectations and answer their pressing concerns; whether alternative principles from different cultures had proven stable and effective in protecting a certain interest; and so on. Arguments also made conceptual points; for example, about the correlation between rights and duties, the relationship between ideal rights and designated duty-bearers, the material conditions for realizing rights, and similar insights. A particularly influential type of argument was one that required a delegate to qualify an overly broad statement of principle in order to ensure that it would not cover obvious cases of injustice - or in the other direction to broaden a statement of principle to ensure it covered paradigm cases of legitimate human freedom or political diversity. Many of the enormously time-consuming debates occurred on these issues of specificity, ensuring the Declaration's wording captured an acceptable breadth for the right in question, with states routinely revising their initial positions on these grounds, sometimes even as soon as the objection was aired (Glendon, 2001; Morsink, 1999). In these ways, parochial, vague or simplistic principles were revised and sharpened.

A final type of change occurred when delegates shifted their position not on the basis of others' persuasive moral arguments, but upon acknowledging that their own arguments were failing to persuade others, and that their stated position was clashing (perhaps sharply) with the majority of other delegations. Shifts in position in this way were particularly common when the delegation realized that its idiosyncratic opposition was (and would be seen as) blocking the process or undermining the consensus necessary for the Declaration's success. In such cases, for example, a state that voted against an amendment in the drafting subcommittee, upon recognizing the majority decision of that subcommittee, would then vote for the amended article when it was returned to the larger quorum. Sometimes a delegation would even retract a proposal before voting if it felt the tide of debate swelling against it. 
It could even be important if a state shifted its stance, not by endorsing the result, but at least by failing to oppose it. This occurred in the Soviet bloc's final voting in the General Assembly in 1948. The bloc still held profound reservations about the Declaration - especially on its articles on freedom of political belief, movement and asylum, and its failure to explicitly condemn fascism (Glendon, 2001; Morsink, 1999). Nevertheless, the Communist States chose to abstain from voting rather than explicitly opposing the Declaration - a move that would have been damaging to their own moral credibility, but potentially fatal to the status of the Declaration itself.

All these three results - exposure of bad faith arguments, change on the basis of persuasive moral argument, and compromise in order to secure a workable result - constitute revisions of states' original assertions. The Declaration was not a record of a consensus existing at the process's beginning, but rather an agreement on a collective construction that saw almost every state at some point shift its position in the course of lengthy dialogue, peer judgments and constructive critique. As a result, bad faith claims were exposed, and good faith (but simplistic or selective) claims were modified, specified, compromised or abandoned, as states moved to positions that were increasingly justifiable from a more impartial third-party perspective.

Of course, we should not overplay the ultimate significance of this outcome. Even with the Declaration concluded in 1948 , it took decades before the first binding international legal treaties achieved ratification, and longer again for human rights to become a genuine force for change in international affairs and domestic politics (Risse \& Sikkink, 1999; Thomas, 2001). But, nor should we undersell what moral dialogue achieved. While human rights challenges still confront every corner of the globe, the days where a simple assertion of state sovereignty could silence dissent and international concern are long past. None of this would have been possible without the lengthy, arduous, challenging process of global moral dialogue undertaken from 1946-1948. 


\section{Ethics after COP20: Principles without dialogue?}

Let us now return to the present day and the ethical challenge of our generation: climate change. We have already seen that mainstream climate discourse involves precious little moral dialogue. Has this changed in the wake of the results of the negotiations at the Lima Conference of the Parties?

The COP20 Outcome Document explicitly invoked ethical concepts, albeit in a somewhat glancing fashion. The Document's Paragraph 14 saw the Conference of the Parties agree that:

...the information to be provided by Parties communicating their intended nationally determined contributions, in order to facilitate clarity, transparency and understanding, may include, as appropriate, inter alia, ... how the Party considers that its intended nationally determined contribution is fair and ambitious, in light of its national circumstances, and how it contributes towards achieving the objective of the Convention as set out in its Article 2; (COP20, 2014b)

Even if we read this paragraph in the context of the invitation of the preceding Paragraph 13 that Parties communicate their INDCs in a manner that facilitates their 'clarity, transparency and understanding', the use of 'may' instead of 'shall' in this requirement presents a clear concern. Parties are invited, but not required, to provide such an account.

But what happens even if this information is supplied? The COP20's Outcome Document makes no mention of any further review and engagement process responding to Parties' claims about their INDC's ambition and fairness, apart from a Secretariat Synthesis Report on the 'aggregate effect' of those INDCs submitted by October 2015 (COP20, 2014b, para. 16b).

The omission of any review process constitutes a serious setback to global mitigation efforts, and does not auger well for the presence of such a mechanism in the post-Paris regime. Yet, the Draft Elements Text with which the Parties entered the Lima negotiations had several promising articles in this regard. And crucially, these articles endure in the Elements Text accepted in Lima 
on December 10, meaning they remain in the ambit negotiating space as the Paris deliberations approach.

The existing Elements Text offers two mechanisms for potentially facilitating a moral dialogue over nation's INDCs and their accompanying explanations of fairness and ambition.

The Elements Text characterizes the first mechanism as an 'ex-ante consideration process' (or consultative period). One of the options for the process's objectives is to 'Assess the adequacy and fairness of the aggregated contributions...' (76). ${ }^{3}$ Options include a consultative process and the use of a principle-based reference framework (perhaps involving a web platform where questions are posed and answers are encouraged), consultations with workshops and roundtables, and a panel examining adequacy and fairness and making subsequent recommendations (76.1, 76.5). Ultimately, this process can result in each Party considering and voluntarily revising its INDC (76.4).

The second mechanism is a 'strategic review of implementation' (or ambition assessment) (Para's. 80-87). This process would review the INDC's implementation, but the assessment can also appraise the ethical adequacy of the INDCs themselves, as it can include:

A process to facilitate the clarity, transparency and understanding of Parties' commitments/contributions, whereby the ambition and fairness of Parties' mitigation commitments can be considered in the light of the long-term temperature limit (Para. 85. Option 1.c) [and/or] Assessment against an equity reference framework by a technical panel of experts (Option 2.e).

\footnotetext{
${ }^{3}$ Parenthetical references are to the Draft Elements Text: (COP20, 2014a).
} 
Through these measures, both the ex-ante consideration mechanism and the strategic review open a space for an official and public dialogue amongst the Parties, perhaps along with dedicated panels and taskforces, about the ethical status of each Parties' INDCs. Parties would then be able to respond to the process' recommendations and outputs. Rather than simply explaining their INDC's 'fairness', Party's initial assertions would be only the first move in a structured dialogue.

To be sure, there is no guarantee that either of these mechanisms will be adopted at Paris - and the weak use of 'may' rather than 'shall' in the COP20 Outcome Document hardly augers well. But State Parties may decide they are all collectively better off if there is at least some method of formally criticising and pressuring Parties whose INDCs appear wanting, and that the ex-ante or strategic review mechanism might offer the best hope in this regard.

\section{Why are the review and consideration mechanisms crucial?}

This Article's first section argued that moral dialogue could help the international community find a fair and effective way forward. In response, some might suppose this result could be secured by (a strengthened version of) Para. 14 of the Outcome Document, which speaks of each state communicating the fairness and adequacy of its INDC. To the contrary however, I argue it is the review mechanisms currently lying dormant in the Elements Text that would prove a lynchpin.

But why? A requirement to provide an ethical justification for one's action, with no prospect of official external review or searching dialogic consideration of that justification, resembles asking a corporation for a public relations version of its latest misdemeanour or inviting a politician to 'spin' her party's latest scandal. There will always be some carefully chosen moral principle, on some appropriately skewed interpretation, applied to some selectively reported version of the fact situation that yields the desired justification. Indeed, recent research on domestic climate change discourses suggest that this process may not be uncommon: most nations appear to select their mitigation policies very much on the basis of national economic interest, and then 
represent those policies as best they can in the international context (Brown \& Taylor, 2014). Critical dialogue, like a persistent journalist in an in-depth interview or an opposing side in a political debate, can expose the appeal to ethics as the rhetorical spin that it is.

But the problem extends beyond 'bad faith' rhetoric, where the state deliberately manipulates ethical language to misrepresent their true position. In many cases, states may feel justified in their stance. Their policies really do follow from (a particular interpretation of) widely held climate principles.

In this case, several problems present themselves. On the one hand, the climate principles themselves may be selectively chosen, and other equally-sensible principles selectively ignored. On the other hand, the interpretation the state gives to a particular principle might itself be extreme or marginal. In both cases (and through the same sorts of rationalizations that conspire against ordinary individuals (Luban, 2003)), the state might place itself in a favourable light through an ethical story that no other agent, not similarly placed, could possibly accept.

This self-interested selection and interpretation could arise in application of climate principles already existing in the Convention (including equity, sustainable development, historic responsibility and 'common but differentiated responsibilities'). Equally though, the state might appeal to other prima facie plausible norms to excuse their lack of effort. The UNESCO Report on the Ethical Implications of Climate Change (COMEST, 2010) surveys an array of potential excuses, including economic losses and the requirement that others (perhaps all others) act equally. Again, state parties may represent these principles as legitimate concerns, but in many instances they will wilt under rational scrutiny.

If these concerns about rhetorical and self-interested justifications sound dismayingly realistic, then in itself a demand for information on fairness and ambition will not facilitate greater mitigation efforts. The result will be that each state provides an ethical justification for its INDCand the cumulative result of the implementation of each of those INDCs (even if all of them were 
implemented faithfully) would be largely business-as-usual economic productivity and potentially catastrophic global warming.

Even without an official review process within the UNFCCC regime, of course, NGOs could provide evaluations of the fairness of each Party's INDC, and publish indexes and rankings capable of publicly shaming poor-performing countries. Doubtless, this would be an important contribution, as greater scrutiny can help expose the more egregious cases of self-serving spin.

Yet, in itself, such scrutiny and external evaluation will not promote a moral dialogue as I have defined that term above (that is, where different Parties publicly engage in a lengthy process of teasing out their moral agreements and disagreements as they search for a principled way forward).

How, then, could moral dialogue help in the context of climate change? The constructive engagement offered by moral dialogue can help each nation see its position from others' perspective, while the ongoing dialogue could aid in specifying the meaning of each of the climate principles, narrowing the available interpretations that can be employed with respect to each. We saw how this occurred in the negotiations over the drafting of the Universal Declaration. As we saw there, argument proceeded by asking common-sense ethical questions, such as: 'Would you accept that principle in an analogous context, or when you were on the receiving end?' Similarly, the dialogue advanced by teasing out qualifications and specifying principles, so that opposing nations found a norm they could both endorse. It exposed excuses previously used by evil regimes (i.e. the Nazis), and ensured the human rights principles were phrased to exclude such duplicity. It appealed to intuitions and paradigm cases where the states shared widespread agreement. Through such everyday methods of engaging with others' moral thoughts and arguments, real progress was made. It is not difficult to envisage the review processes employing very similar devices to challenge Parties' explanations of the fairness of their INDCs. Doubtless, some Parties will propose different ethical positions from each other, and 
each with some degree of legitimacy. (Many disagreements are no doubt fuelled by selfinterested selection; but it is a general truth about such deliberations that substantial disagreements - genuine ethical disputes - remain even when self-interest is removed (Muldoon et al., 2014).) But the most obviously bad-faith justifications will be exposed, and opposing goodfaith positions may be mitigated as Parties seek to capture within their own standpoint the intuitive and reasonable aspects of others' positions.

None of this supposes that the situation with climate mitigation analogizes perfectly to that of human rights. Moral dialogue is hard work; it requires compromise, sensitivity, diplomacy, an admission of one's fallibility and the time and patience to painstakingly negotiate difficult and subtle concerns. The 1940 s saw the galvanizing force for such dialogue in the enormity of the Second World War and the horrors of the Nazi regime. Such a disaster no doubt spurred the international community to engage in a process, and construct a result that might have been impossible at any other period in the Twentieth Century. Climate change has occasioned no such large-scale, visible catastrophe to drive ordinary people to demand that international moral dialogue take place, and this difference might ultimately stymie the prospects of realising such a dialogue.

\section{Conclusion}

I have argued that asking states to offer a moral defense of their INDCs, while welcome, will probably not induce greater efforts to combat climate change through mitigation. Just as in the case of human rights, states will likely prove more than capable of rhetorically dressing up their selfinterested activities in prima facie seductive moral language. However, just as in the case of human rights, I submit that an ongoing dialogic enquiry into the principles justifying Parties' INDCs could expose bad faith grandiloquence and improve selectively-chosen interpretations of ethical principles. Both the ex-ante consideration process and the strategic review mechanism (each currently lying dormant in the Elements Text) include processes that would allow dialogic question 
and critique, common-sense moral argument, reflective revision and compromise, public peer judgment and expert assistance - all of the key building blocks that facilitated the extraordinary consensus on human rights captured in the Declaration.

Naturally, I cannot pretend such dialogue will prove a panacea to all the substantial blocks facing strong global action on climate change. Indeed, there is every possibility the human rights drafting process itself would have collapsed if not for the confluence of extraordinary personalities including Rene Cassin, P. C. Chang, Charles Malik and Eleanor Roosevelt - who undertook to drive the project through to its fruition. Even so, such a process of critical dialogue and constructive argument could, as one part of a larger effort, bring states closer to an agree ment on actions that are genuinely fair and ambitious.

\section{References}

ILA (International Law Association) (2014). Legal Principles Relating to Climate Change Report of the International Law Association's Committee on Legal Principles Relating to Climate Change Washington: ILA.

Aristotle. (2002). Nicomachean ethics (J. Sachs, Trans.). Newbury, MA: Focus Publishing/R. Pullins.

Beitz, C. (2009). The Idea of Human Rights. New York: Oxford University Press.

Benjamin, M. (1990). Splitting the Difference: Compromise and Integrity in Ethics and Politics. Kansas: University of Kansas.

Brown, D. A. (2013). Climate Change Ethics: Navigating the Perfect Moral Storm. London and New York: Routledge.

Brown, D. A., \& Taylor, P. (Eds.). (2014). Ethics and Climate Change. A Study of National Commitments. Gland: IUCN.

Christoff, P. (2013). Climate Discourse Complexes, National Climate Regimes and Australian Climate Policy. Australian Journal of Politics and History, 59(3), 349-367. 
COMEST. (2010). The Ethical Implications of Climate Change. Paris: UNESCO.

COP20, Conference of the Parties (2014a). Elements for a draft negotiating text. Lima: UN FCCC.

COP20, Conference of the Parties (2014b). Report of the Ad Hoc Working Group on the Durban Platform for Enhanced Action. Lima: UN FCCC.

Dreben, B. (2003). On Rawls and Political Liberalism. In S. Freeman (Ed.), Cambridge Companion to Rawls (pp. 316-346). Cambridge: Cambridge University Press.

Finnemore, M., \& Sikkink, K. (1998). International Norm Dynamics and Political Change. International Organisation, 52(4), 887-917.

General-Assembly, U. N. (1948). Universal Declaration of Human Rights (UDHR).

Glendon, M. A. (2001). A world made new: Eleanor Roosevelt and the Universal Declaration of Human Rights. New York: Random House.

Hume, D. (1969). A Treatise of Human Nature. Baltimore, Md.: Penguin Books.

IPCC (Intergovernmental Panel on Climate Change) (1992). United Nations Framework Convention on Climage Change. Rio.

Knight, C. (2012). What is Grandfathering? Environmental Politics, 22(3), 410-427.

Luban, D. (2003). Integrity: Its Causes and Cures. Fordham Law Review, 72(2), 279-310.

Maclntyre, A. (1981). After virtue: a study in moral theory. London: Duckworth.

Maguire, R. (2012). Incorporating International Environmental Legal Principles into Future Climate Change Instruments. Carbon and Climate Law Review, 2012(2), 101-113.

Maguire, R. (2013). The Role of Common but Differentiated Responsibility in the 2020 Climate Regime: Evolving a New Understanding of Differential Commitments. Carbon and Climate Law Review, 4, 1-10.

Morsink, J. (1999). The Universal Declaration of Human Rights: Origins, Drafting and Intent. Philadelphia: University of Pennsylvania.

Muldoon, R., Lisciandra, C., Colyvan, M., Martini, C., Sillari, G., \& Sprenger, J. (2014). Disagreement behind the veil of ignorance. Philosophical Studies(170), 377-394. 
Okereke, C. (2010). Climate justice and the international regime. Climate Change, 1(3), 462-474.

Ostrom, E., \& Hess, C. (2007). Private and Common Property Rights. from http://papers.ssrn.com/sol3/papers.cfm?abstract_id=1304699

Ott, K. (2011). Domains of Climate Ethics. Jahrbuch für Wissenschaft und Ethik, 95-114.

Rawls, J. (2005). Political Liberalism (Expanded ed.). New York: Columbia University Press.

Risse, T., \& Sikkink, K. (1999). The socialization of international human rights norms into domestic practices. In T. Risse, S. C. Ropp, \& K. Sikkink (Eds.), The Power of Human Rights: International norms and domestic change (pp. 1-38). New York: Cambridge University Press. Thomas, D. (2001). The Helsinki Effect: International Norms, Human Rights, and the Demise of Commuism. Oxford: Princeton University Press. 